\title{
PRECISION AGRICULTURE: AN INTEGRATION OF INFORMATION TECHNOLOGIES WITH FARMING
}

\author{
R.D. BUICK
}

\author{
Trimble Navigation NZ Ltd., 11 Birmingham Drive, P.O. Box 8729, \\ Riccarton, Christchurch, New Zealand
}

\begin{abstract}
Precision agriculture or site specific farming is guiding farmers towards a new approach to their farm and resource management. It has been defined as 'farm management based upon variable soil and microclimate conditions within fields'. The development and integration of a range of technologies has enabled their application to agriculture. Precise positioning in real time via Global Positioning Systems (GPS), the use of digital maps, Geographic Information Systems (GIS) and computers on-board agricultural vehicles are some of the main technologies. Currently, these technologies are providing ways to map fields and topographic features, navigate to sampling /scouting sites, monitor and map withinfield yield variations, apply variable agrochemical applications via prescription maps and allow parallel swath guidance. Automated record keeping is another significant benefit of precision farming, assisting with environmental compliance and management record keeping. Many other supporting technologies are being researched and applied to precise farm management. This paper presents an overview of current precision agricultural systems, where these technologies are progressing and discusses the potential and actual benefits of precision agriculture.

Keywords: Precision agriculture, site specific farming, Global Positioning Systems, GPS, Geographic Information Systems, GIS.
\end{abstract}

\section{INTRODUCTION}

Precision agriculture or site specific farming has been touted as the next revolution in agriculture! Whether this is technology hype or reality, precision agriculture is certainly receiving a great deal of media coverage. Precision agriculture, also referred to as Site Specific Farming, or Site Specific Management has come about from a number of technologies reaching a level of sophistication. The advancement of these technologies allows them to be applied to agriculture and integrated in ways that farmers, custom applicators, crop consultants, cooperatives and agribusinesses can use them to better monitor and manage within-field variability. The result appears to be a very 'high-tech' transformation of agriculture (Wilson 1997). But the "jury is still out", and is likely to be so for some time yet, on the economic andreal returns to growers who are implementing this technology. However, objectivity in the assessment of precision agricultural products and effectiveness of these methodologies is gaining in momentum (Rund 1997; Sray 1996).

Agribusinesses, cooperatives and agronomic consultants are typically the first to adopt precision agriculture, empowering themselves with a new range of services that they can provide to farmers or growers. Farmers will typically adopt yield monitoring and yield mapping as the first aspect of precision agriculture to invest in. Yield monitoring is generally accepted as the first important step in precision agriculture to be adopted. Collecting yield maps over several years of cropping in a particular field is a good step towards improving the understanding of the inherent within-field variability. It may take at least several years before consistent patterns of variability can be identified in an agricultural field. This is due to the large number of variables that may influence yield, the time for agronomists and soil scientists to become fully equipped at handling and

Proc. 50th N.Z. Plant Protection Conf. 1997: 176-184 
interpreting such huge quantities of detailed spatio-temporal agronomic data, and the time it will take to verify findings over several seasons in order to determine precise economic returns and benefits from implementing precision agricultural practices. Crop management for pests and the use of integrated pest management (IPM) techniques is influenced by precision agriculture where greater detail and level of information about crops and potential pest problems can be identified, monitored and controlled (Dunn 1996).

In spite of the many unknowns about the precision agricultural movement, it is certainly an exciting, emerging and rapidly developing area. The primary technologies involved today are merely the first (i.e. Global Positioning Systems, Geographic Information Systems, Remote Sensing imagery and variable rate controller technologies). The application and integration of these preliminary technologies to agriculture is opening opportunities to a whole new range of other technologies which could be incorporated into the process. This paper endeavours to provide some insight into precision agriculture today, describes typical applications of these technologies today and where it may lead in the future.

What is Precision Agriculture?

Precision agriculture can be thought of as a process, which involves the collection, interpretation, planning and/or use of data about a field and a particular crop (or sequence of crops) (Fig. 1). Currently, the precision agricultural process can be divided up into several events or agricultural tasks:

- $\quad$ Field and spatial feature mapping

- Soil sampling

- Crop scouting

- Swath guidance for agrochemical applications

- Application logging and automated record keeping

- Variable rate applications based on prescription maps

- Geographic Information Systems (GIS) to store, manipulate, analyse and interpret the spatio-temporal data collected over the farm and to generate prescription maps for an agrochemical application to a field

Each of these steps uses a combination of one or both of the following technologies (although there can be other technologies implicated in many of the steps):

- Global Positioning Systems (GPS)

- Geographic Information Systems (GIS)

\section{The Global Positioning System (GPS)}

Global Positioning Systems (GPS) can be thought of as a tool to provide us with positions or locations on the earth (directions $\mathrm{x}$ and $\mathrm{y}$, elevation $\mathrm{z}$ ) and the exact time that the position was collected. This can be applied to many areas, not just agriculture, where navigation, guidance, vehicle tracking, surveying or mapping might be required. In fact, GPS has an almost infinite range of applications and is often referred to as the next utility. GPS has come about from the US Department of Defence's constellation of 24 satellites which are orbiting the earth at approximately $20,000 \mathrm{~km}$ high. These satellites contain highly accurate atomic clocks which are constantly orbiting the earth so that at any one time, at least 3 satellites are visible from any location on the earth. Each GPS satellite transmits a radio signal towards the earth. A GPS receiver is able to detect the GPS satellite signal (a radio wave). By determining the distances from the GPS receiver to the 'visible' satellites, the position of the receiver on the earth can be derived using a minimum of 3 satellite signals. Distance from a receiver to one satellite is determined by timing how long a radio wave takes to travel from the satellite to the receiver, with distance determined from velocity. These timings are determined using the highly accurate clocks on board the satellites.

GPS alone is not as accurate as it needs to be for many applications. A form of correction is required to reduce several sources of error (e.g., satellite clock error, atmospheric and equipment conditions, Selective Availability or SA). The largest source of error is the US Department of Defence's intentional error setting, called Selective Availability (SA), which is set on GPS satellites to deny hostile forces the tactical advantage of GPS positioning (Hurn 


\section{Precision Agricultural Process:}

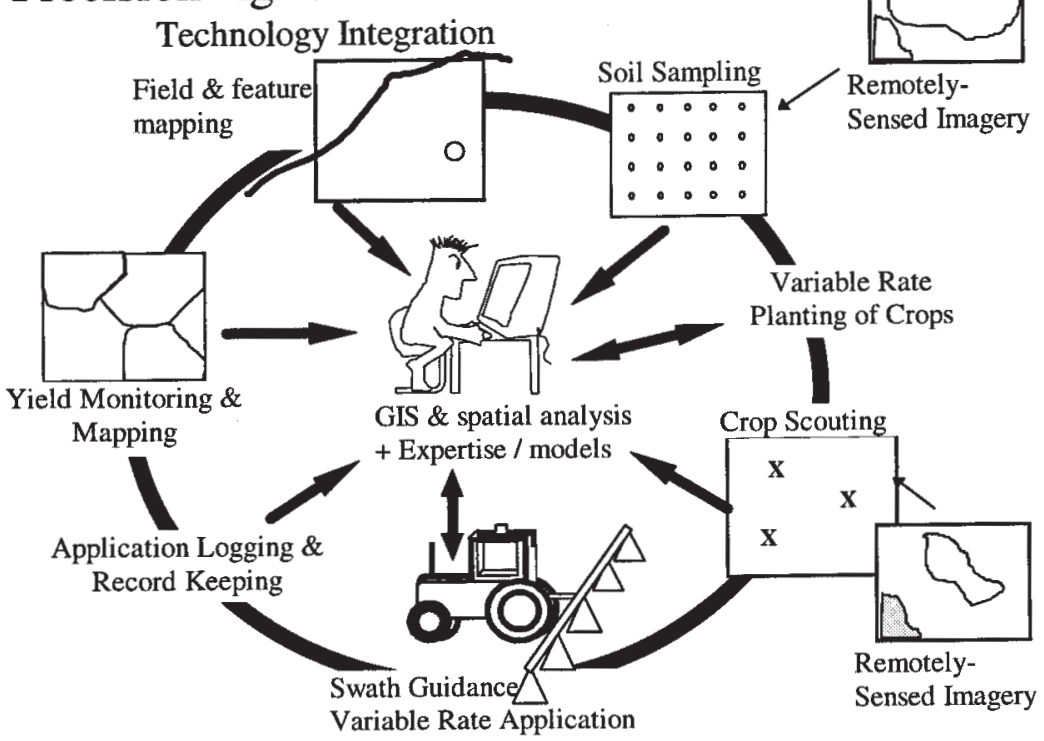

\section{FIGURE 1: Typical steps in the precision agricultural process.}

1989). One method of obtaining more accurate positions is called Differential GPS (DGPS) which is the most commonly used form of corrected GPS positioning in precision agriculture today. Typical position accuracy using DGPS is $1 \mathrm{~m}$ or less with the high quality DGPS receivers on the market today. A GPS receiver with a source of differential correction allows farmers to map the exact locations of field boundaries, rocks, trees, streams, tracks, avoidance zones or other hazards. Given that most agricultural equipment has a width or boom of anywhere from 10 to 30 metres wide, a 1 metre or less accuracy is generally sufficient.

A Geographic Information System(GIS), is the other information technology implicated in precision agriculture, used for computer mapping. GIS can be thought of as a spatial database where spatial data can be stored as points, lines, polygons or raster (cell) features. GIS also allows you to store attributes about each spatial feature and perform spatial analysis on the spatial data. GIS allows layers of geo-referenced maps to be overlayed, analysed (e.g., intersections, unions, closest distance type functions) and displayed. GIS is a tool to assist with the storage, display and interpretation of spatial data that might be collected using a GPS receiver. The precision agricultural movement has produced a significant amount of farm-based mapping software which is either a GIS software package customised for precision agriculture or is a very simple map-making package, which strictly-speaking, is not a true GIS.

A number of other technologies are sometimes used in precision agriculture such as remote sensing, variable rate application controller technology, but these vary depending on each specific agricultural task and the level of investment by the user. Some of these other technologies are discussed further below.

\section{The Precision Agricultural Process}

The precision agricultural process can be divided into several steps (Fig. 1). Activities that are commonly performed within each of these steps are described in detail below. Field and Spatial Feature Mapping

DGPS receivers are being set up on agricultural vehicles for a variety of precision 
agricultural tasks. One function of these receivers is to initially map fields and any other spatial features of importance to the farmer. For example field boundaries, streams, tracks, avoidance zones, weed areas, disease outbreak sites, rocks and other hazards. Accurate records of field acreages, field and farm maps are not only useful for many farm managers, but there is a growing emphasis on accurate management records from environmental authorities, particularly in Europe and North America. Typically, these features and many spatial layers are collected and stored in an office-based system, usually a GIS.

There are a number of other ways that field boundaries and spatial features can be collected and loaded into a GIS. For example, boundaries and features can be derived or scanned from maps based on aerial photographs, older maps or survey data. However, this kind of information often proves inadequate and inflexible if you wish to combine various sets of spatial data which have come from different sources (Stevens 1996). There are cases where agribusiness applicators have driven to the wrong fields to apply fertilizer or pesticides as the map information loaded into the applicator's system told the operator to apply a field which was several hundred metres off the correct field (Stevens 1996).

\section{Crop Yield Monitoring and Mapping}

Yield monitoring and mapping is one step in precision agriculture which is often recommended as a first step to carry out in precision agriculture (Krill 1996) Yield monitors are developed by specialized agricultural engineering companies and can be bought to retrofit into existing combine harvesters. Otherwise, many heavy agricultural companies (e.g. CASE IH, John Deere, Klaus, Massey Fergusson etc) have been releasing new series of combine harvesters onto the market which have built-in DGPS receivers, a yield monitor and a moisture monitor. A yield monitor, often a flow sensor device, is used to determine the crop yield as it is harvested. Moisture monitors can be installed to record a value for crop moisture level; this can be used to obtain a continuous readout of crop moisture content and/or used for dry matter yield determinations. At each time or distance interval at which a yield value is taken (e.g., operator can set it up to be every 1 second or every $10 \mathrm{~m}$ for example), the DGPS will record a position value (or fix). The yield and position data is recorded and stored onto an on-board computer and/or PCMCIA card or disk. The farmer can down-load the yield data to their office computer at night and create a yield map for that field where the yield variations are easily depicted using different colours. These maps can be useful ways to learn more about the field management and driving variables causing high or low yields within the field (Morrell 1996; West pers. comm.).

It has been stated that 3-5 years of yield maps need to be collected on a field in order to observe repeatable patterns in a field's yield variation (Colvin 1996; Lachapelle et al. 1996) and to maximise the utility of this information by combining it with a variety of other spatial data on the field (Stafford et al. 1996). It may require at least this period of in-field experimentation by most growers before the benefits of yield map information can be truly realised. Although cereal, corn and soybean crop yield monitors have been the most readily available yield monitors to date, research and development efforts are constantly expanding the variety of yield monitors for various crop (e.g., potato yield monitors, Hollist et al. 1996).

\section{Soil Sampling}

Detailed soil sampling has become possible by the integration of GPS and GIS tools available to precision agriculture. Many agribusinesses or consultants are performing soil sampling as a service for growers. Soil sampling is typically done by generating a sampling pattern for a field, often according to a grid pattern. The sampling grid consists of cells (typically 2.5 acre grids in the US) where each cell is designated a sample site or point (Fig. 2). Sample points are either in the centre of each grid cell (aligned, Fig. 2) or positioned randomly within the cell (unaligned, Fig. 2).

There are many other sampling patterns and techniques that can be used. The choice of which sampling regime is the subject of much debate amongst soil scientists and agronomists involved in precision agriculture (Berry 1996). The purpose of the sampling is to be as representative of the field as possible to map the field soil fertility status as 

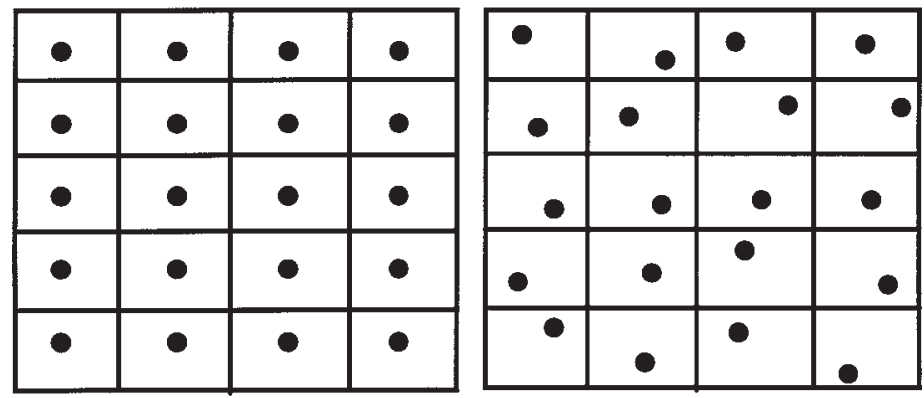

FIGURE 2: Aligned (left) and unaligned (right) soil sampling patterns.

accurately as possible (Soil Improvement Committee California Fertilizer Association 1995) but within economically feasible limits for the grower. Some of the different sampling approaches in addition to the aligned and unaligned grid are staggered start, random cluster and random start patterns (Berry 1996). Other more complex sampling methods are being evaluated (e.g. area testing or 'smart grids') which involve the consideration of other spatial layers (maps) prior to defining the sampling regime. For example, aerial photography or satellite-based imagery (e.g., crop foliage imagery, bare soil imagery or other information derived from multispectral imagery), soil maps, yield or topography maps can be used to identify distinctions in landforms, soil types or other variables which are known to influence soil fertility. These can be used to delineate regions in the field so sampling can be focussed in particular regions and reduce the sampling intensity that the grower is prepared to pay for and/or the operator is prepared to carry out.

A GPS-based graphical display or navigational device (e.g., bull's eye or light bar) is then used to help the soil sampling operator navigate towards each of the sample sites. Samples from each site are placed in bags, identifying each sample with a unique identification, such as a bar code label on the sample bags. Bar code readers or wands are often connected to a GPS-based computer system which allows the operator to 'swipe' the bar codes to record the unique identification. The field-based DGPS system is then used to record the current location that the sample was taken from and all of this information is saved a data file. The data file is then transferred to a GIS. Once the soil laboratory testing is completed, the results can be added to this data file. The GIS can be used to interpolate between the sample points to create a soil fertility surface map or contour map. For example, the results might be a map of nitrate level variations across the field or a map of soil $\mathrm{pH}$ levels. Some of the precision agricultural GIS software specialise in providing a wide range of interpolation techniques to create the fertility maps (e.g. SSToolbox which is developed by SST Development Group ${ }^{1}$, as a high level precision agricultural GIS system based on the ESRI ${ }^{2}$ ArcView GIS system), while others allow the user to create maps simply and quickly via a single interpolation method (e.g., JDmap mapping software ${ }^{3}$ ).

Soil fertility surfaces (maps) can be combined with yield variation maps in a GIS to determine if there are any relationships between fertility variables (e.g., $\mathrm{pH}$, nitrate,

${ }^{1}$ SST Development Group, Inc., 824 North Country Club Road, Stillwater, OK 74075 0918, USA.E-mail: sst@sstdevgroup.com Web: http://www.sstdevgroup.com

2 ESRI, Environmental Systems Research Institute, Inc., 380 New York Street, Redlands, CA 92373-8100, USA.E-mail: info@esri.comWeb: http://www.esri.com

${ }^{3}$ John Deere Precision Farming Systems, Greenstar Combine Yield-Mapping System with JDmap office mapping software 
phosphorus levels) and yields.

\section{Crop Scouting}

Crop scouting is being advocated as another process that can benefit from precision agricultural technologies. A grower may randomly spot problems in a field and with an appropriate DGPS data recording system on board, can easily record that point so subsequent control measures can be taken (e.g. spot spraying for weed, disease or insect pest occurrence). By recording the point, the grower can easily navigate back to the problem spot at a different time, using navigational devices as used for soil sampling, to control the problem.

Remotely sensed imagery is also being applied to mid-season crop management (Hanley 1997; Petersonet al. 1995). Aerial photography and/or satellite-based imagery are being collected to provide growers with images and information on their crop health during the crop growth season. Different types of imagery can provide different information about the crop. For example, infrared imagery can be used to identify plant health and nutrition problems, while other spectral bands provide better information about soils and weed infestations (Spry 1996).

Advances in satellites for remote sensing will provide agriculture with an enhanced set of information (Petersonet al. 1995). A new generation of satellites for imagery will offer spatial, spectral and temporal resolutions that have never been available to the public (Hanley 1997). Several major private companies have invested heavily in these new satellite services (Carlson and Patel 1997). EarthWatch is one example who are building a constellation of commercial imaging satellites. The initial configuration consists of two EarlyBird satellites, the first of which was launched in the first quarter of 1997. Two QuickBird satellites are planned by the same organisation for 1998. EarlyBird has a 3 metre resolution panchromatic sensor and a 15 metre resolution multi-spectral sensor. QuickBird features a 0.82 metre resolution panchromatic sensor and a 3.28 metre resolution multispectral sensor. These kinds of resolutions (approximately 1 metre or smaller) are indicative of where satellite imagery is heading, with much of this imagery being available over medium such as the World Wide Web. This level of spatial imagery can provide useful information to identify crop health or pest problems. Several organisations and agribusinesses are setting up with the appropriate equipment to collect large amounts of satellite imagery, to then process and interpret the images for their growers. Problem areas are marked so these points can be navigated to using a DGPS receiver. By ground truthing, the grower can be sure that the problem is what the officebased diagnostic process claimed. Over time, the ability to diagnose from these images in the office will improve and remove the need for a significant amount of ground truthing.

\section{Variable Rate Application of Agrochemicals}

Having collected large amounts of spatial and temporal information for a field (e.g., after several years of soil sampling and yield monitoring), one of the final steps in precision agriculture is to automatically vary the fertilizer and/or pesticide inputs on the field as the spreader/sprayer truck drives across the field.

To perform variable rate application, there is an important GIS-based process where one or more spatial layers for a field are used to determine a prescription map which prescribes the optimum or suitable rates of application. Many precision agricultural GIS software packages allow the user to generate prescription maps based on past yield maps and/or soil fertility maps derived from the soil sampling process. One way this might be done is to allow the GIS user to formulate their own 'optimum' equations for fertiliser, lime and/or pesticide rates based on known spatio-temporal variables (map layers) in the field such as $\mathrm{pH}$, soil nitrate levels, drainage properties etc. The resultant map would be the prescription map that would be loaded into an on-board field computer that drives the variable rate applicator. Another way of obtaining the prescription maps is to use standard agronomist-approved formulas for optimum application rates given soil characteristics or climatic and other regional variations for that particular crop. A great deal of research and a number of crop growth models are being developed which will help to automate this prescription generation process, for example research using decision support systems that growers can access (e.g., over the internet) or regional models can be 
integrated into the user's own precision agricultural GIS software.

Some regions have environmental concerns (e.g., water quality) where natural resource authorities are encouraging farmers to consider environmental spatial variables in the formulation of the variable rate prescription map (Peterson et al. 1995; Blackmer and Schepers 1996). For example, a risk map of groundwater sensitivity to contamination might be used to adjust application rates of nitrogen fertilisers or manure applications so the higher risk areas receive lower rates of nitrogen For several years environmental agencies such as the US Environmental Protection Agency (EPA) have been using complex simulation models to evaluate pesticide impacts on catchments (e.g. Young et al. 1989; Srinivasan and Arnold 1993; Goddard et al. 1996) and/or to help screen new pesticides (National Agricultural Chemicals Association 1994). By combining these approaches with more detailed farm and field-based spatio-temporal and management information, more accurate and detailed soil and land use monitoring will be possible.

Variable rate applications are done by setting up a DGPS system on a spreader truck or spraying unit along with an on-board processor (computer) capable of importing and interpreting the prescription map. The operator can drive the vehicle about the field with the system automatically regulating the application rates based on the vehicle location. Variable rate application control devices are also involved in the process since the onboard computer sends the prescribed application rate for each location, usually set to occur at a distance or time based interval, to the variable rate controller system which in turn regulates the output rate of the spray boom or the application channels on the spreading equipment.

\section{Swath Guidance}

Another significant advantage of the DGPS technology is the ability to guide the field operator along parallel swathing patterns or along particular patterns of swathing that the operator desires to follow. Typically this is used with pesticide applications or fertiliser spreading situations where it can be difficult to see where previous passes (swaths) were made. Although foam marker systems have been used for some time to provide guidance to the applicator, a number of problems exist with these such as dissipation of the foam before the operator can use it for the next pass, the operator still needs to estimate by eye where to turn and line up alongside the foam from the previous swath which can be difficult with a $30 \mathrm{~m}$ or longer spray boom, wind can make foam drift causing gaps or overlaps in applications, and the application must be done in daylight (Kohls 1996). Differential GPS for parallel swath guidance removes the foam drift problem, can make it possible for the operator to apply for longer hours, operate at night, operate in foggy or snow conditions. It is important to note how this can improve pesticide efficacy under conditions of high humidity (e.g., at night or in fog) where plant-chemical surface contact and plant uptake of chemicals can be significantly improved. In some crops the nocturnal behaviour of crop leaves is such that the undersides of leaves where particular insect pests tend to reside are more exposed.

The primary purpose of using DGPS for parallel swath guidance is to improve the application or coverage of the material onto a field by being able to easily identify the skips or overlaps in applications to a field. Some precision agricultural systems used for parallel swath guidance will display a graphical map in the field, with the areas already applied as shaded or coloured swaths so the operator can quickly identify areas which have not been applied to. This allows the operator to return to sites that have been missed and rectify the problem while they are still in the field.

\section{The Future of Precision Agriculture}

Some may be wondering how far these "high tech" tools can advance in agriculture. It is certain that precision agriculture is at an early stage of development. It is also likely that advances in and new precision agricultural technologies will be a major preoccupation of researchers and product developers over at least the next 5-10 years. Autonomous tractors are already being researched (O'Connor 1996) and a huge variety of 'on-the-go' sensors will extend the ability to collect information about a field's variability as a vehicle passes over an agricultural field (e.g., soil nutrient and soil texture sensors, light reflectance-based sensors for soil moisture and organic matter) (Hummell et al. 1996; Morgan 1996). 
Some realities about precision agriculture will undoubtedly appear over the next few years of its application in mainstream agriculture. There will be a growing amount of information at the farmer's fingertips which could present an 'information overload' problem unless it is carefully managed. Markwart (1996) warns of the growing demand for data processing and interpretation services for farmers, as even high-tech farmers will become inundated with data and time to process and organise their data. Automation of the data processing and interpretation processes is likely to develop further (e.g., simulation models or decision support systems to prescribe agrochemical rates based on known spatial variables affecting crop growth).

Ownership of all this data is a matter of consideration as growing environmental pressures and agencies will wish to better track activities on farms, with many precision agricultural systems being able to automatically generate records. Other incentives for farmers to keep good management records include market price incentives (e.g. proof of applying minimum or no inputs to crops can return higher premiums) and farm land values may be judged on the level of record keeping and evidence that agrochemical inputs were minimised.

\section{SUMMARY}

Precision agriculture is a rapidly developing field. Although there is a degree of scepticism about the utility of such high technology tools in agriculture, there are numerous precision agriculture users who are observing significant benefits from applying site specific management on their farms, such as those obtained from guidance, yield monitoring, soil sampling, crop scouting. Results from the global "experimentation" of site specific management and the growing emphasis on objective evaluations of precision agricultural products on the market will accelerate the rate at which precision agriculture is assessed. The optimum precision agriculture methods may vary across different crops, soils and climates. There is a simultaneous need for traditional research methodologies such as agronomy, soil science and pest management to apply and integrate a wider range of technologies such as remote sensing, GIS and GPS across their research, thereby maximising the learning potential from the precision agriculture experiment.

\section{REFERENCES}

Berry, J. Sampling patterns. @ g/INNOVATOR June 1996: 4.

Blackmer, T.M. and Schepers, J.S. 1996. Using DGPS to improve corn production and water quality. GPS World (March 1996) :44-52.

California Fertilizer Association, 1995. Soil and Tissue Testing. Pp.189-214. In: Western Fertilizer Handbook. Soil Improvement Committee California Fertilizer Association, 8th edition, Interstate Publishers, Inc. Danville, Illinois, USA.

Carlson, G.R. and Patel, B., 1997. A new era dawns for geospatial imagery. GIS World 10(3): 36-40.

Colvin, T., 1996. Lessons from seven years of consecutive yield maps. Proceedings of the 1996 Information Agriculture Conf. (July 30-August 1 1996, University of Illinois): $72-73$.

Dunn, R., 1996. IPM gets another close look. Dealer Progress (April/May 1996):1618.

Goddard, T., Kryanowski, L., Cannon, K., Izaurralde, C. and Martin, T. 1996. Integrated GIS-EPIC model for precision farming.. Poster presentation in Proceedings of the 1996 Information Agriculture Conference, July 30 - August 1 1996, University of Illinois: 5.

Hanley, C., 1997. Satellite imagery brings focus to the field. Modern Agriculture 1(1): 17-19.

Hollist, R., Wollman, A. and Campbell, R. 1996. No small potatoes: Monitoring the yield of high-value crops.Precision Farming. Supplement toGPS World Magazine, July 1996: 24-28.

Hummell, J.W., Gautlney, L.D. and Sudduth, K.A. 1996. Soil property sensing for site- 
specific crop management. Computers and Electronics in Agric. 14:121-136.

Hurn, J., 1989. GPS. A Guide to the Next Utility. Trimble Navigation Ltd., 645 North Mary Avenue, P.O. Box 3642, Sunnyvale, CA 94088-3642, USA.

Hurn, J., 1993. Differential GPS explained. An expose of the surprisingly simple principles behind today's most advanced positioning technology. Trimble Navigation Ltd., 645 North Mary Avenue, P.O. Box 3642, Sunnyvale, CA 94088-3642, USA.

Kohls, C. 1996. The GPS Challenge. Precision Farming. Supplement to GPS World Magazine, July 1996: 29-31.

Krill, T.L. 1996. Yield monitors. Proceedings of the 1996 Information Agriculture Conf., July 30 - August 1 1996, University of Illinois: 39-40.

Lachapelle, G., Cannon, M.E., Penney, D.C. and Goddard, T., 1996. GIS/GPS facilitates precision farming. GIS World, July 1996: 54-56.

Markwart, A. 1996. Who will crunch your yield data ? Prairie Farmer (June 1996).

Morgan, M.T., 1996. Soil sensor update.Proceedings of the 1996 Information Agriculture Conf., July 30 - August 1 1996, University of Illinois: 21-22.

Morrell, D., 1996. The secrets of the soils: Analyzing Western Australia's dry land wheatbelt. Precision Farming, supplement to GPS World Magazine: 10-17.

National Agricultural Chemicals Association, 1994. Primary, secondary and screening models for pesticide registration. FIFRA Exposure Modeling Work Group (EMWG), c/o National Agricultural Chemicals Association, 1156 Fifteenth Street, N.W. Suite 400, Washington D.C. 20005, USA.

Peterson, G.W., Bell, J.C., McSweeney, K., Nielson, G.A., and Robert, P.C. 1995. Geographic Information Systems in Agronomy. Advances in Agronomy 55: 67111.

Rund, M., 1997. Choosing the right site-specific technologies for agriculture. Modern Agriculture 1(1): 10-15.

Spry, K., 1996. Air surveillance. Aerial photography poinpoints pest problems. Farm Chemicals, June $1996: 24$.

Sray, A., 1996. Do GPS costs make sense ? Farm Chemicals (June 1996): 20-22.

Srinivasan, R. and Arnold, J.G. 1993. Basin scale water quality modeling using GIS. Proc. Application of Advanced Information Technologies: Effective Management of Natural Resources, 18-19 June 1993, Spokane, Washington: 475-484.

Stafford, J.V., Ambler, B., Lark, R.M. and Catt, J., 1996. Mapping and interpreting the yield variation in cereal crops. Computers and Electronics in Agric. 14:101-119.

Stevens, J., 1996. Precision farming field boundary maps: How precise are yours? AgRetailer: 46-47.

Wilson, J.D., 1997. Precision agriculture: Farming goes high tech.Modern Agric. 1(1): 21-23.

Young, R.A., Onstad, C.A., Bosch, D.D. and Anderson, W.P. 1989. AGNPS: A nonpoint-source pollution model for evaluating watersheds. J. Soil and Water Conserv. (Mar/April) :168-173. 